\title{
Gelir ve Servet Vergileri Türkiye'de Gelir Dağılımını Etkilemekte midir?
}

\section{Do Income and Wealth Taxes Affect Income Distribution in Turkey?}

\author{
Güray Akalin a,* \\ ${ }^{a}$ Dr. Öğr. Üyesi, Kütahya Dumlupınar Üniversitesi, İktisadi ve İdari Bilimler Fakültesi, İktisat Bölümü, Kütahya / TÜRKiYE \\ ORCID: 0000-0002-6647-5418
}

\section{MAKALE BİLGISI}

Makale Geçmişi:

Başvuru tarihi: 31 Aralık 2020

Düzeltme tarihi: 21 Ocak 2021

Kabul tarihi: 27 Ocak 2021

\section{Anahtar Kelimeler:}

Gelir Vergisi

Servet Vergisi

Gelir Dağılımı

ARDL sinır testi

\section{ARTICLE INFO}

\section{Article history:}

Received 31 December 2020

Received in revised form 21 January 2021

Accepted 27 January 2021

Keywords:
Income Tax
Wealth Tax
Income Distribution
ARDL bound test

\section{ÖZ}

Bu çalışmanın temel amacı gelir ve servet vergilerinin gelir dağılımı üzerindeki etkilerini Türkiye için 1987-2016 yıllarını kapsayan verileri kullanarak incelemektir. Ampirik analizler sonucu elde edilen bulgular şöyle sıralanabilir: i) modelde yer alan değișkenlerin durağanlık özellikleri I(1) ve I(0) olmak üzere farklılık göstermektedir ii) değişkenler arasında eşbütünleşme ilişkisi vardır iii) uzun dönemde transfer harcamalarında, gelir ve servet vergilerinde ortaya çıkan bir artıs gelir dağılımı eşitsizliğini azaltmaktayken, ișsizlik ve enflasyonda ortaya çıkan bir artış gelir dağılımı eşitsizliğini arttırmaktadır. Gelir dağılımı eşitsizliğini azaltmada servet vergisi de gelir vergisi kadar etkin olduğundan servet vergisinin kullanımı yaygınlaştırılmalıdır.

\section{Giriş}

Son yirmi yılda dünyanın birçok ülkesinde gelir dağılımı eşitsizliğinde bir artış yaşanmış, 2008 krizi ile birlikte ise bu artış hızlanmıştır (Martinez-Vazquez vd. 2012: 2). Artan eşitsizlik sadece ahlaki ve etik açıdan değil, kalkınma ve refah üzerindeki bozucu etkilerinden dolayı da kaygı ve endişe yaratmıştır (Goñi vd. 2008: 1). Zira yüksek eşitsizlik rant arama faaliyetlerine, sosyal gerilime, politik istikrarsızlığa, fakir orta seçmenin var olmasına, kusurlu sermaye piyasasına ve orta sınıfın gelirden daha düşük pay

\footnotetext{
* Sorumlu yazar/Corresponding author.

e-posta: guray.akalin@dpu.edu.tr
}

almasına yol açarak ekonomik büyümeyi yavaşlatabilmektedir (Nissanke ve Thorbecke, 2006: 1343).

Gelirin faktör piyasalarındaki dağılımı sonrası ortaya çıkan bu eşitsizliği azaltmaya yönelik devletin elindeki en önemli maliye politikası araçları vergi ve transfer harcamalarıdır. Her ne kadar vergilerin temel amacı kamu harcamalarını finanse etmek olsa da, vergiler cari açığı düșürmek, iktisadi etkinliği arttırmak ve gelir dağılımı eşitsizliğini azaltmak gibi amaçlar doğrultusunda da kullanılmaktadır (Prasad, 2008: 6; Joumard vd. 2012: 38; Bükey ve Çetin, 2017:107; Demirgil, 2018: 120). Vergiler kişilerin kullanılabilir gelirini değiştirerek gelir dağılımını doğrudan etkileyebildikleri gibi 
bireylerin hem yatırım hem de işgücü kararlarıyla ilgili ekonomik teşviklerini değiştirerek gelir dağılımını dolaylı yoldan da etkileyebilirler. Örneğin vergi kompozisyonundaki bir değişim yüksek gelir grubunda yer alan bireylerin kullanılabilir gelirini azaltarak gelir dağılımını doğrudan etkileyebileceği gibi üretimi azaltarak ve dolayısıyla işsizliği arttırarak gelir dağılımını dolaylı yoldan da etkileyebilir (Drucker vd. 2017: 2; Ciminelli vd. 2019: 1).

Gelir eşitsizliklerinin dünya çapında yaygınlaşması, yeniden dağıtım için hangi vergilerin daha aktif kullanılması gerektiği konusunda bir tartışmayı tetiklemiş ve görece yeni bir literatürün oluşmasına yol açmıştır (Prasad, 2008: 1). İlgili literatür incelendiğinde vergilerin gelir dağılımı üzerindeki etkisi araştırılırken genellikle vergilerin çeşitli kriterlere göre sinıflandırıldığı ve etkinliklerinin karşılaştırıldığı görülmektedir. Bu sınıflandırma yapılırken en fazla kullanılan kriter ise verginin konusudur. Konusu itibariyle vergiler dolaylı ve dolaysız vergiler olmak üzere ikiye ayrılmaktadır. Dolaylı vergiler (katma değer vergisi, özel tüketim vergisi, gümrük vergisi vb.) harcama üzerinden alınan vergiler iken dolaysız vergiler (gelir vergisi, kurumlar vergisi, servet vergisi vb.) gelir ve servet üzerinden alınan vergilerdir (Demirgil, 2018: 120). Literatürde dolaylı vergilerdeki bir artışın gelir dağılımı eşitsizliğini arttırdığı, dolaysız vergilerdeki bir artışın ise gelir dağılımı eşitsizliğini azalttığı yönünde bir fikir birliği vardır. Dolaysız vergiler arasında yer alan gelir ve servet vergilerinin ise mükellefin bireysel ve ailevi durumunu dikkate almaları, artan oranlı tarife yapıları ve yansitabilmelerinin kolay olmaması nedeniyle gelir dağılımı eşitsizliğini azaltmada en etkili vergiler olduğu vurgulanmaktadır (Kanca ve Bayrak; 2019: 1498; Eser ve Genç, 2020:224). Bununla birlikte, bu teorik beklentinin ampirik olarak test edilmesi ve hangi verginin gelir dağılımı eşitsizliğini azaltmada daha etkin olduğunun ortaya konulması, gelir dağılımı eşitsizliğini azaltmaya yönelik oluşturulacak politikaların etkinliğini arttıracaktır. Buradan hareketle bu çalışmanın temel amacı 1987-2016 dönemini kapsayan verileri kullanarak Türkiye'de gelir ve servet üzerinden alınan vergilerin gelir dağılımı üzerindeki etkisini ampirik olarak ortaya koymaktır. Araştırıldığı kadarıyla bu çalışma gelir ve servet vergilerinin gelir dağılımı üzerindeki etkisini Türkiye örneğinde inceleyen ilk çalışmadır. Bu nedenle de literatüre önemli bir katkı sağlayacağı düşünülmektedir.

\section{Literatür Taraması}

Vergi kompozisyonunun makro ekonomik değişkenler üzerindeki etkisinin incelendiği nispeten yeni ve büyüyen bir literatür söz konudur. İlgili literatürün önemli bir parçasını da vergi-gelir dağılımı eşitsizliği ilişkisini elen alan çalışmalar oluşturmaktadır. Hem Türkiye örneğini hem de diğer ülke örneklemlerini inceleyen bu çalışmalardan bazıları şöyle özetlenebilir:

Gregorio ve Lee (2002), 1960 ile 1990 yılları arasında Afrika, Asya, Latin Amerika ve OECD ülkelerinde eğitim seviyesinin ve sosyal transfer harcamalarının gelir dağılımını nasıl etkilediğini araştırmışlardır. SUR yönteminin kullanıldığ 1 çalışmada, eğitim seviyesindeki ve sosyal transfer harcamalarındaki artışın gelir dağılımı eşitsizliğini azaltmada önemli faktörler olduğu tespit edilmiştir. Prasad (2008), vergi ve harcamaların gelir eşitsizliği üzerindeki etkilerini altı Latin Amerika ülkesi ile OECD ülkeleri arasında bir karşılaştırma yaparak incelemiştir. Analizler sonucunda vergi ve transferlerdeki artışların her iki ülke grubunda da eşitsizliği azalttığı ancak etkinin OECD ülkelerinde çok daha büyük olduğu tespit edilmiştir. Ayrıca, doğrudan vergilerdeki artışların gelir dağılımı eşitsizliğini azalttığı, dolaylı vergilerdeki artışların ise gelir dağılımı eşitsizliğini arttırdığı ifade edilmiştir. Sameti ve Rafie (2010), İran ve seçilmiş Doğu Asya ülkelerinde çeşitli vergilerin gelir dağılımı üzerindeki etkisini 1990-2006 dönemi için incelemişlerdir. Rassal Etkiler yönteminin kullanıldığ1 çalışmada, mal ve hizmetler üzerinden alınan vergilerin gelir dağılımı üzerindeki etkisinin istatistiksel olarak anlamsız olduğu, kar ve sermayeden alınan vergilerin ise teorik beklentilerin aksine gelir dağılımı eşitsizliğini arttırdığı tespit edilmiştir. Martinez-Vazquez vd. (2012), gelişmişlik düzeyleri farklı 150 ülkede 1970-2006 dönemi için vergilerin ve kamu harcamalarının gelir dağılımı üzerindeki etkilerini incelemişlerdir. Fark GMM yönteminin kullanıldığı çalışmada, artan oranlı kişisel gelir vergisinin ve kurumlar vergisinin gelir dağılımını olumlu etkilediği, genel tüketim vergileri, tüketim vergileri ve gümrük vergilerinin ise gelir dağılımını olumsuz etkilediği tespit edilmiştir. Ayrıca kamu kesiminin gerçekleştirdiği sosyal refah, eğitim, sağlık ve konut harcamalarının da gelir dağılımını olumlu etkilediği belirlenmiştir. Bilgiç (2015), vergilendirme politikalarının gelir dağılımı üzerindeki etkilerini Türkiye için 1990-2013 dönemini kapsayan veriler ile araştırmıştır. En Küçük Kareler (EKK) yönteminin kullanıldı̆̆ dolaylı vergilerin etkisinin istatiksel olarak anlamsız olduğu, dolaysız vergilerdeki artışın ise gelir dağılımı eşitsizliğini azalttığı saptanmıştır. Cevik ve Correa-Caro (2015), 19802013 dönemini kapsayan y1llk verileri kullanarak 33 gelişmekte olan ülkede maliye politikalarının gelir dağılımına etkilerini incelemişlerdir. GMM tahmincisinin kullanıldığı çalışmada, literatürün aksine kamu harcamalarındaki artışın gelir dağılımı üzerinde bozucu bir etkisinin olduğu, vergilerdeki artışın ise gelir dağılımı üzerinde düzeltici bir etkisinin olduğu bulguları elde edilmiştir. Balseven ve Tugcu (2017), 1990-2014 y1lları arasında 17 gelişmekte olan ve 30 gelişmiş ülkede vergi ve transferlerin gelir eşitsizliği üzerindeki etkilerini doğrusal panel veri tahmin teknikleri kullanarak analiz etmişlerdir. Çalışmada vergi gelirlerindeki artışların hem gelişmiş hem de gelişmekte olan ülkelerde gelir dağılımı eşitsizliğini azalttığı, sosyal yardımlardaki artışların ise gelişmiş ülkelerde gelir dağılımı eşitsizliğini azalttığı, gelişmekte olan ülkelerde ise etkisinin istatiksel olarak anlamsız olduğu belirlenmiştir. Bükey ve Çetin (2017), çeşitli makro ekonomik büyüklüklerin gelir dağılımı üzerindeki etkilerini Türkiye için incelemişlerdir. 1980-2014 dönemini kapsayan yıllık verilerin ve EKK yönteminin kullanıldığı çalışmada vergi yükünün gelir dağılımı üzerindeki etkisinin istatiksel olarak anlamsız olduğu belirtilmiştir.

Drucker vd. (2017), 1975-2011 dönemini kapsayan yıllık verileri kullanarak, verisine ulaşabildikleri 25 OECD ülkesinde çeşitli vergilerin gelir dağ 1 lımı üzerindeki etkisini incelemişlerdir. Sabit Etkiler tahmincisinin kullanıldığı çalışmada elde edilen bulgular şöyle sıralanabilir: i) Gelir vergisindeki artış gelir dağılımı eşitsizliğini azaltmaktadır. Ancak gelir vergisi, ücretler ve sermaye kazançları üzerinden alınan vergiler şeklinde ikiye ayrıldığında, ücretler üzerinden alınan verginin gelir dağılımı eşitsizliğini azalttı̆̆ 1 , sermaye kazançları üzerinden alınan verginin ise 
gelir dağılımı eşitsizliğini arttırdığı tespit edilmiştir. ii) Servet vergisindeki artış gelir dağılımı eşitsizliğini arttırmaktadır. Ancak servet vergisi tekrarlanan (belediye vergisi vb.) ve tekrarlanmayan (emlak vergisi, veraset vergisi vb.) servet vergisi şeklinde ikiye ayrıldığında, tekrarlanan servet vergilerinin gelir dağılımı eşitsizliğini arttırdığı, tekrarlanmayan servet vergilerinin ise gelir dağılımı eşitsizliğinin azalttığ 1 tespit edilmiştir. iii) Tekrarlanmayan servet vergilerinin gelir dağılımı eşitsizliğini düzeltici etkisi gelir vergisinin düzeltici etkisinden daha yüksektir iv) Tüketim üzerinden alınan dolaylı vergiler gelir dağılımı eşitsizliğini arttırırken, kurumlar vergisinin etkisi istatiksel olarak anlamsızdır. Demirgil (2018), 1980-2014 döneminde Türkiye'de dolaylı ve dolaysız vergilerin gelir dağılımını nasıl etkilediğini incelemiştir. ARDL yönteminin kullanıldığı çalışmada dolaylı vergilerdeki artışın gelir dağılımı eşitsizliğini arttırdığı, dolaysız vergilerdeki artışın ise gelir dağılımı eşitsizliğini azalttığı tespit edilmiştir. Teyyare ve Sayaner (2018), Türkiye'de 1990-2016 döneminde vergilerin, kamu harcamalarını ve kamu borçlanmalarının gelir dağılımı üzerindeki etkilerini araştırmışlardır. EKK yönteminin kullanıldığı çalışmada, vergilerdeki ve kamu harcamalarındaki artışların gelir dağılımı eşitsizliğini azalttığı, kamu borçlarındaki artışın ise gelir dağılımı eşitsizliğini arttırdığı bulgularına ulaşılmıştır. Ciminelli vd. (2019), 16 OECD ülkesinde 1978-2012 y1lları arasında dolaylı ve dolaysız vergilerin gelir dağılımını ne yönde etkilediğini panel VAR yöntemi ile araştırmışlardır. Ampirik analizler sonucunda vergiye dayalı konsolidasyonların ekonomik faaliyetteki daraltma pahasına hem piyasa hem de harcanabilir gelir üzerinden hesaplanan eşitsizliği azalttığı ve dolaylı vergilerin dolaysız vergilere göre gelir eşitsizliğini daha fazla azalttığı tespit edilmiştir. Günel (2019), Türkiye için dolaylı ve dolaysız vergilerin gelir dağılımı üzerindeki etkisini Johansen eşbütünleşme analizi ile araştırmıştır. 1987-2016 dönemini kapsayan verilerin kullanıldığı çalışmada, dolaylı vergilerdeki artı̧̧ların gelir dağılımı eşitsizliğini arttırdığı, dolaysız vergilerdeki artışın ise gelir dağılımı eşitsizliğini azalttığ belirtilmiştir. Kanca ve Bayrak (2019), 36 OECD üyesi ülkede dolaylı ve dolaysız vergilerin gelir dağıllımı üzerindeki etkilerini 1990-2017 dönemi için incelemişlerdir. FMOLS ve DOLS tahmincilerinin kullanıldı ̆̆ hem dolaylı hem de dolaysız vergilerdeki artışın gelir dağılımı eşitsizliğini arttırdığı belirlenmiştir. Zaman vd. (2019), gelişmişlik düzeyleri farklı 63 ülkede gelir dağılımının belirleyicilerini Beta regresyon yöntemi ile araştırmışlardır. Çalışmada vergi gelirlerindeki artışın gelir dağılımı eşitsizliğini azalttığı bulgusu elde edilmiştir. Eser ve Genç (2020), 1990-2017 yılları arasında OECD ülkelerinde servet ve gelir üzerinden alınan vergilerin gelir dağılımı eşitsizliğini hangi yönde etkilediğini araştırmışlardır. Arellano, Froot ve Rogers tahmincisinin kullanıldığı çalışmada, hem servet hem de gelir vergisindeki artışların gelir dağılımı eşitsizliğini azalttığ yönünde bulgu elde etmişlerdir. Bununla birlikte, servet vergisinin gelir vergisine kıyasla gelir dağılımı eşitsizliğini azaltmada daha etkin olduğu belirlenmiştir.

Yukarıda özetlenen çalışmalarla ilgili genel bir değerlendirme yapıldığında şu noktalar dikkat çekmektedir: i) Çalışmaların büyük bir çoğunluğu dolaylı ve dolaysız vergilerin ve transfer harcamalarının gelir dağılımı üzerindeki etkilerini incelemiştir. Farklı bulgulara ulaşan çalışmalar olsa da, çalışmaların önemli bir kısmı dolaysız vergilerin ve transfer harcamalarının/kamu harcamalarının gelir dağılımı eşitsizliğini azalttığı, dolaylı vergilerin ise gelir dağılımı eşitsizliğini arttırdığı sonucuna ulaşmışlardır. ii) Gelir ve servet vergilerinin gelir dağılımı üzerindeki etkilerinin karşılaştırmalı incelendiği çalışma sayısı oldukça sınırlıdır. Ayrıca, araştırıldığı kadarıyla bu ilişkiyi Türkiye örneğinde ele alan çalışma bulunmamaktadır. Literatürdeki bu boşluğu doldurmak ve literatüre ampirik katkı sağlamak amacıyla bu çalışmada, gelir ve servet vergilerinin gelir dağılımı üzerindeki etkileri Türkiye için karşılaştırmalı olarak incelenmiştir.

\section{Model ve Veri Seti}

Gelir ve servet vergilerinin 1987-2016 yılları arasında Türkiye'de gelir dağılımı eşitsizliğini ne yönde ve ne büyüklükte etkiledikleri aşağıda yer alan tam logaritmik doğrusal model yardımıyla incelenmektedir.

$$
Y_{t}=\beta_{0}+\beta_{1} \operatorname{LnX} 1_{t}+\beta_{2} \operatorname{LnX} 2_{t}+\beta_{3} \operatorname{Ln} X 3_{t}+\beta_{4} \operatorname{LnX} 4_{t}+\beta_{5} \operatorname{LnX} 5_{t}+\varepsilon_{t}
$$

Burada $Y$, piyasa geliri üzerinden hesaplanmış Gini katsayısı (Gini market) ile kullanabilir gelir üzerinden hesaplanmış Gini katsayısı (Gini disposable) arasındaki farktır. Gini katsayısı vergi ve transfer öncesi piyasa geliri üzerinden hesaplanabildiği gibi transfer ödemelerinin eklenip dolaysız vergilerin düşülmesi sonrası elde edilen kullanılabilir gelir üzerinden de hesaplanabilmektedir (Solt, 2020: 1187-1188). İki Gini katsayıs1 arasındaki fark ise yeniden dağııım etkisi olarak adlandırılmakta ve transfer harcamalarının ve dolaysız vergilerin gelir dağılımını ne yönde etkilediğini göstermektedir. Bu nedenle bu çalışmada bağımlı değişken olarak iki Gini katsayısı arasındaki fark kullanılmıştır. Bağımsız değişkenler X1 ve X2 sırasıyla gelir ve servet vergilerinin GSYH içerisindeki payını, ihmal edilmiş değişken sapmasına yol açmamak için modele eklenen kontrol değişkenleri X3, X4 ve X5 ise sırasıyla transfer harcamalarını, işsizlik ve enflasyon oranlarını temsil etmektedir. Gini katsayılarına ait veriler Standartlaştırılmış Dünya Gelir Eşitsizliği Veri tabanından, gelir vergisi, servet vergisi ve transfer harcamalarına ait veriler OECD veri tabanından, işsizlik ve enflasyon verileri ise Dünya Bankası veri tabanından elde edilmiştir. Çalışmanın analizleri Eviews 9 programı kullanılarak gerçekleştirilmiştir.

\section{Ampirik Yöntem ve Bulgular}

\subsection{Birim Kök ve Durağanlık Analizi}

Modeli en uygun ekonometrik analizler ile tahmin edip etkin tahminciler elde edebilmek için ilk olarak değişkenlerin durağanlık özellikleri saptanmalıdır. Buradan hareketle ampirik analizin birinci aşamasında değiş̧enlerin durağanlık özellikleri Dickey ve Fuller (1981) tarafindan geliştirilen Genişletilmiş Dickey-Fuller (Augmented Dickey Fuller-ADF) birim kök testi ve Kwiatkowski vd. (1992) tarafindan geliştirilen KPSS (Kwiatkowski Phillips, Schmidt ve Shin) durağanlık testiyle incelenmiştir. ADF birim kök testinin yokluk hipotezinde birim kök, KPSS durağanlık testinin yokluk hipotezinde ise durağanlığın test ediliyor olması sapmalı hipotez kabulünün önüne geçecektir (Erdoğan, 2020: 216). Her iki testin de sonucu aşağıda Tablo 1 'de yer almaktadır.

Tablo 1. Birim Kök ve Durağanlık Testi Sonuçları 


\begin{tabular}{|c|c|c|c|c|}
\hline \multicolumn{5}{|c|}{ ADF } \\
\hline & Seviye & \multicolumn{3}{|c|}{ Birinci Fark } \\
\hline & $\mathrm{C}$ & $\mathrm{C}+\mathrm{T}$ & $\mathbf{C}$ & $\mathrm{C}+\mathrm{T}$ \\
\hline \multirow[t]{2}{*}{$\mathbf{Y}$} & & - & - & \\
\hline & $0.77(0.991)$ & $2.39(0.373)$ & $5.11(0.000)$ & $5.53(0.000)$ \\
\hline \multirow[t]{2}{*}{ X1 } & - & - & - & \\
\hline & $0.88(0.777)$ & $3.28(0.090)$ & $4.38(0.001)$ & $4.30(0.010)$ \\
\hline \multirow[t]{2}{*}{$\mathbf{X} 2$} & - & - & - & - \\
\hline & $3.27(0.025)$ & $5.50(0.000)$ & & \\
\hline \multirow[t]{2}{*}{$\mathbf{X 3}$} & - & - & - & \\
\hline & $1.57(0.484)$ & $1.92(0.617)$ & $4.65(0.000)$ & $4.72(0.004)$ \\
\hline \multirow{2}{*}{ X4 } & - & - & - & - \\
\hline & $2.30(0.176)$ & $3.23(0.099)$ & $4.21(0.003)$ & $4.14(0.015)$ \\
\hline \multirow{2}{*}{ X5 } & - & - & - & \\
\hline & $0.85(0.789)$ & $\begin{array}{c}1.38(0.843) \\
\text { KPSS }\end{array}$ & $4.67(0.000)$ & $4.57(0.005)$ \\
\hline $\mathbf{Y}$ & $0.85[50$. & $0.138[10.1]$ & $0.44[0.10]$ & - \\
\hline X1 & $0.39[22.3]$ & $0.11[6.22]$ & - & - \\
\hline $\mathbf{X} 2$ & $0.63[3.47]$ & $0.07[0.59)$ & $0.10[2.44]$ & - \\
\hline $\mathbf{X 3}$ & $0.48[28.3]$ & $0.05[0.78]$ & $0.17[1.21]$ & - \\
\hline X4 & $0.33[8.24]$ & $0.07[5.72]$ & - & - \\
\hline X5 & $0.47[27.1]$ & $0.12[11.2]$ & $0.16[0.73]$ & - \\
\hline
\end{tabular}

Not: " $C+T$ " trend ve sabitli modeli, " $C$ " ise sabitli modeli temsil etmektedir. ADF testinde maksimum gecikme uzunluğu 2 olarak alınmış olup, optimal gecikme sayısının belirlenmesinde Akaike Bilgi Kriteri'nden faydalanılmıştır. KPSS testinde \%5 anlamlllık düzeyinde sabitli modelde kritik değer 0.463, sabitli ve trendli modelde ise 0.146'dir. KPSS testinde optimal gecikme saylsinın belirlenmesinde Andrews Bandwidth opsiyonundan faydalanılmıştır. Parantez içeresinde yer alan değerler olasılık değerlerii, köşeli parantez içerisinde yer alan değerler ise gecikme sayılarıdır.

Tablo 1 incelendiğinde; ADF ve KPSS testlerinin değişkenlerin durağanlık özelliklerine yönelik farklı bulgular ortaya koyduğu görülmektedir. Bununla birlikte her iki teste göre de değişkenler ya seviyede ya da birinci farklarında durağanlaşmaktadırlar.

\subsection{Eşbütünleşme Analizi}

Modelde yer alan bağımsız değişkenlerden bazıları seviyede durağan olduğundan, bu çalışmada değişkenler arasındaki uzun dönem ilişki Pesaran ve Shin (1999) ve Pesaran vd. (2001) tarafından geliştirilen ARDL (Autoregressive Distributed Lag) sınır testi yaklaşımı ile incelenmiştir. ARDL yaklaşımının diğer eşbütünleşme testlerine göre önemli bazı avantajları söz konusudur ve bunlardan bazıları şöyle sıralanabilir: i) ARDL sınır testi için değişkenlerin tamamının aynı seviyede durağanlaşmalarına gerek yoktur. Ancak serilerin I(2) olmasi durumunda bu test kullanılamamaktadır. ii) ARDL testi örneklemin küçük ya da bazı regresörlerin içsel olması durumunda bile etkin bir tahmincidir. iii) Modele eklenen değişkenler için farklı gecikme sayıları belirlenebilmektedir iv) İndirgenmiş denklem yardımıyla modelin kısa ve uzun dönem katsayıları aynı anda tahmin edilebilmektedir.

ARDL sınır testi yaklaşımında temel iki aşama söz konusudur. İlk aşamada kısıtsız hata düzeltme modeli (ECM) ile değişkenler arasındaki uzun dönemli ilişki araştırılmaktadır. Eğer ilk aşamada değişkenler arasında uzun dönemli bir ilişki bulunursa ikinci aşamaya geçilmekte ve modelin kısa ve uzun dönem katsayıları tahmin edilmektedir. $\mathrm{Bu}$ çalışmada kullanılan kısıtsız ECM aşağıdaki 2 nolu denklemde gösterilmektedir:
$\Delta Y_{t}=\beta_{0}+\sum_{i=1}^{p} \beta_{n i} \Delta X_{t-i}+\delta_{n} X_{t-1}+\varepsilon_{t}$

Burada Y bağımlı değişkeni, X bağımsız değişkenler setini, $\varepsilon_{t}$ hata terimini ve $\Delta$ ise değişkenlerin birinci farkını temsil etmektedir. ARDL sinır testi, yokluk hipotezinin $\left(H_{0}: \delta_{n}=0\right)$ alternatif hipoteze $\left(H_{1}: \delta_{n} \neq 0\right),(n=1,2,3,4$. $)$ karşı F-testi veya Wald testi aracılığıyla sınanmasına dayanmaktadır. ARDL sınır testi yaklaşımında yokluk hipotezi "değişkenler arasında eşbütünleşme ilişki yoktur" şeklindeyken, alternatif hipotez "değişkenler arasında eşbütünleşme ilişkisi vardır" şeklindedir (Ozturk ve Acaravci, 2013: 264; Acaravc1 vd. 2019: 9). ARDL sinır testi sonuçları aşağıda Tablo 2'de, CUSUM (cumulative sum) ve CUSUMSQ (cumulative sum of squares) testlerinin sonuçları ise Grafik 1'de gösterilmektedir.

Tablo 2. ARDL Sonuçları

\begin{tabular}{|c|c|c|}
\hline $\begin{array}{l}\text { Eşbütünleşme } \\
\text { Analizi }\end{array}$ & F İstatistiği & $\begin{array}{l}\text { \%95 alt sınır }-\% 95 \\
\text { üst sinır }\end{array}$ \\
\hline $\begin{array}{l}\operatorname{ARDL}(2,0,2,1, \\
1,1)\end{array}$ & 5.35 & $2.39-3.38$ \\
\hline $\begin{array}{l}\text { Uzun Dönem } \\
\text { X1 } \\
\text { X2 } \\
\text { X3 } \\
\text { X4 } \\
\text { X5 }\end{array}$ & $\begin{array}{c}\text { Katsayı } \\
0.30 * \\
0.27 * * * \\
0.18 * * * \\
-0.43 * * * \\
-0.15 * * *\end{array}$ & $\begin{array}{l}\text { t-istatistiği[olasılık] } \\
1.82[0.087] \\
4.23[0.000] \\
3.41[0.003] \\
-3.62[0.002] \\
-8.97[0.000]\end{array}$ \\
\hline $\begin{array}{l}\text { Hata Düzeltme } \\
\text { Modeli }\end{array}$ & & \\
\hline $\begin{array}{l}\Delta \mathrm{Y}(-1) \\
\Delta \mathrm{X} 1\end{array}$ & $\begin{array}{l}-0.35^{* *} \\
0.07\end{array}$ & $\begin{array}{r}-2.49[0.024] \\
1.47[0.162]\end{array}$ \\
\hline$\Delta X_{2}$ & $\begin{array}{l}0.02 * \\
-0.06 * * *\end{array}$ & $\begin{array}{l}1.93[0.072] \\
-3\end{array}$ \\
\hline $\begin{array}{l}\Delta X 2(-1) \\
\Delta X 3\end{array}$ & $\begin{array}{l}-0.06 * * * \\
-0.03\end{array}$ & $\begin{array}{l}-3.71[0.002] \\
-0.62[0.541]\end{array}$ \\
\hline$\Delta \mathrm{X} 4$ & -0.03 & $-0.82[0.419]$ \\
\hline$\Delta \times 5$ & -0.02 & $-1.56[0.137]$ \\
\hline Ect & $-0.37 * * *$ & $-7.22[0.000]$ \\
\hline Tanı Testleri & İstistik[olasılık] & \\
\hline Ramsey-Reset & $1.14[0.347]$ & \\
\hline Breusch-Godfrey & $1.73[0.214]$ & \\
\hline $\begin{array}{l}\text { Breusch-Pagan- } \\
\text { Godfrey }\end{array}$ & $0.72[0.708]$ & \\
\hline Jarque-Bera & $1.07[0.585]$ & \\
\hline
\end{tabular}

Grafik 1: Cusum ve Cusum Kare (Cusum ve Cusumq) Testi Sonuçları
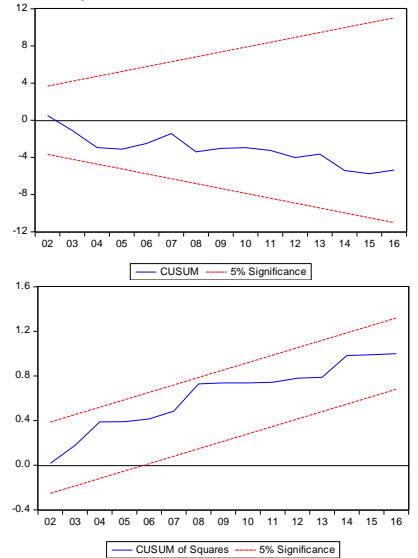
ARDL sınır testinin sonuçları incelendiğinde; en uygun modelin ARDL $(2,0,2,1,1,1)$ olduğu, hesaplanan $\mathrm{F}$ istatistik değerinin ise 5.35 olduğu görülmektedir. Hesaplanan $\mathrm{F}$ istatistik değeri $\% 5$ anlamlılık düzeyindeki kritik üst sınır değerinden (3.38) büyük olduğu için yokluk hipotezi reddedilmekte ve değişkenler arasında uzun dönemli bir ilişki olduğu sonucuna varılmaktadır.

Değişkenler arasında uzun dönemli bir ilişki saptandığından bir sonraki aşamada modelin kısa ve uzun dönem katsayıları tahmin edilmiştir. Tahmin edilen uzun dönem katsayılar incelendiğinde; katsayıların tamamının istatiksel olarak anlamlı olduğu ve işaretleri itibari ile teorik beklentilere uyumlu oldukları görülmektedir. Buna göre gelir vergisinde, servet vergisinde ve transfer harcamalarındaki bir artış Gini market ile Gini disposable arasındaki farkı arttırarak (daha küçük bir Gini disposable ortaya çıkararak) gelir dağılımı eşitsizliğini azaltırken, işsizlik ve enflasyondaki bir artış gelir dağılımı eşitsizliğini arttırmaktadır. Gelir dağılımı eşitsizliğini azaltmada gelir vergisi servet vergisinden daha etkin olsa da katsayıların birbirine oldukça yakın oldukları görülmektedir. Diğer taraftan gelir dağılımının en önemli belirleyicisinin işsizlik olduğu tespit edilmiştir. Çalışmada elde edilen uzun dönemli bulguların Gregorio ve Lee (2002), Prasad (2008), Martinez-Vazquez vd. (2012), Bilgiç (2015), Demirgil (2018), Teyyare ve Sayaner (2018), Ciminelli vd. (2019), Günel (2019) ve Zaman vd. (2019) ile uyumlu olduğu, Sameti ve Rafie (2010), Cevik ve Correa-Caro (2015), Bükey ve Çetin (2017), Drucker vd. (2017), Kanca ve Bayrak (2019) ve Eser ve Genç (2020) ile ise uyumsuz olduğu görülmektedir.

Kısa dönem katsayılar değerlendirildiğinde; servet vergisine ve modele bağımsız değişken olarak eklenen bağımlı değişkenin gecikmeli değerine ait katsayıların istatistiksel olarak anlamlı olduğu, diğer katsayıların ise anlamsız olduğu görülmektedir. Hata düzeltme katsayısı ise -0.37 olup istatistiksel olarak anlamlıdır. Buna göre uzun dönemli dengeden sapmalar yaklaşık üç dönem içerisinde düzelmektedir. Son olarak modelin geçerliliği ve güvenilirliğini test etmek amacıyla bazı tanı testleri gerçekleştirilmiştir. $\mathrm{Bu}$ tanı testlerinin sonuçları incelendiğinde; hata terimleri arasında ilişki olmadığı, hata terimi varyansının sabit olduğu, hata terimlerinin normal dağıldığ edilen katsayıların 1987-2016 dönemleri arasında istikrarlı olduğu saptanmıştır.

\section{Sonuç ve Politika Önerileri}

Gelir dağılımındaki eşitsizliğin dünya genelinde yaygınlaşması, yeniden dağıtım için hangi vergilerin daha etkin olduğunun araştırılmasına yönelik görece yeni bir literatürün doğmasına yol açmıștır. İlgili literatüre katkı sağlamak amacıyla bu çalışmada gelir ve servet vergilerinin gelir dağılımı üzerindeki etkileri Türkiye için 1987-2016 dönemini kapsayan yıllık veriler ile araştırılmıştır. İncelendiği kadarıyla bu çalışma gelir ve servet vergilerin gelir dağılımı üzerindeki etkilerini Türkiye örneğinde araştıran ilk çalışmadır. Bu nedenle de literatürdeki önemli bir boşluğu dolduracağı düşünülmektedir.
ARDL yaklaşımı ile elde edilen bulgular ve bu bulgulara dayalı bazı politika önerileri şöyle sıralanabilir: uzun dönemde gelir ve servet vergisindeki bir artış gelir dağglımı eşitsizliğini azaltmaktadır ve etkinlikleri itibariyle her iki verginin de birbirine oldukça yakın oldukları saptanmıştır. Buna karşın Türkiye'de 1987-2016 yılları arasında toplam gelir vergisinin GSYİH'a oranı ortalama \%4 iken toplam servet vergilerinin GSYİH'a oranı sadece \%0.74'tür. Oysa servet gelir yaratıcı bir özelliğe sahiptir ve dağılımında da ciddi eşitsizlikler söz konusudur. Bundan dolayı servet vergilerinin arttırılmasının ve yaygınlaştırılmasının gelir dağılımı eşitsizliğini azaltmada önemli bir faktör olacağı söylenebilir.

İşsizlik ile birlikte gelir dağılımı eşitsizliği yükselmektedir. İşsizliğin gelir dağılımı eşitsizliğini arttırıcı etkisi yaygın olarak bilinmekte ve literatürde bir fikir birliği bulunmaktadır. İşsizlikteki artış hem daha fazla bireyin gelirini kaybetmesine sebep olarak, hem de ücret pazarlıklarında işgücü aleyhine baskı yaratarak reel ücret artışlarını sınırladığından gelir dağılımı eşitsizliğini arttırabilmektedir. $\mathrm{Bu}$ nedenle politika yapıcılar sürdürülebilir istihdam olanaklarını arttıracak geniş ölçekli makroekonomik politikalar tasarlamalıdır.

Transfer harcamalarındaki artış gelir dağılımı eşitsizliğini azaltmaktadır. İyi tasarlanmış transfer harcamaları eğitim ve sağlık hizmetlerine erişimde firsat eşitsizliğini azaltarak gelir dağılımı eşitsizliğini düzeltebilir. Bu sebepten ötürü transfer harcamalarının kamu harcamaları içerisindeki payı arttırılmalı, denetleme, teşvik ve yaptırım mekanizmaları sağlıklı bir şekilde kurgulanmalı ve süreç şeffaf bir şekilde yönetilmelidir.

Son olarak, enflasyondaki bir artış gelir dağılımı eşitsizliği arttırmaktadır. Yüksek gelirli bireylerin enflasyondan korunma amaciyla finansal piyasalara erişimi düşük gelirli bireylerden daha fazla olduğundan ve enflasyon ile birlikte daha çok emek geliri elde eden düşük gelirlilerin reel geliri azaldığından, enflasyondaki artış gelir dağılımı eşitsizliğini arttırabilir. Bundan dolayı karar vericiler fiyatlar genel düzeyinde istikrarı sağlayacak politikalar geliştirmelidir.

\section{Kaynakça}

Acaravcı, A., Akalin, G., \& Erdoğan, S. (2019). Araştırmageliştirme harcamalarının Türkiye ihracatına etkileri. Hacettepe Üniversitesi İktisadi ve İdari Bilimler Fakültesi Dergisi, 37(1), 1-16.

Balseven, H., \& Tugcu, C. T. (2017). Analyzing the effects of fiscal policy on income distribution: A comparison between developed and developing countries. International Journal of Economics and Financial Issues, 7(2), 377.

Bilgiç A. (2015). Türkiye'de uygulanan vergilendirme politikalarının gelir dağılımı üzerindeki etkileri: 1990-2013 dönemi. Eskişehir Osmangazi Üniversitesi. Sosyal Bilimler Enstitüsü, Eskişehir.

Bükey, A. M., \& Çetin, B. I. (2017). Türkiye'de gelir dağılımına etki eden faktörlerin en küçük kareler yöntemi ile analizi. Maliye Araştırmaları Dergisi, 3(1), 103-117. 
Cevik, S., \& Correa-Caro, C. (2019). Growing (un) equal: fiscal policy and income inequality in China and BRIC+. Journal of the Asia Pacific Economy, pp. 120.

Ciminelli, G., Ernst, E., Merola, R., \& Giuliodori, M. (2019). The composition effects of tax-based consolidation on income inequality. European Journal of Political Economy, 57, 107-124.

Demirgil, B. (2018). Vergilerin gelir dağilimi üzerindeki etkisi: Ampirik bir çalişma. Cumhuriyet Üniversitesi İktisadi ve İdari Bilimler Dergisi, 19(2), 118-131.

Dickey, D. A., \& Fuller, W. A. (1981). Likelihood ratio statistics for autoregressive time series with a unit root. Econometrica: Journal of the Econometric Society, pp. 1057-1072.

Drucker, L., Krill, Z. E., \& Geva, A. (2017). The 1mpact of tax composition on income inequality and economic growth. (Erişim: 25.11.2020) https://www.mof.gov.il/en/PublicationsAndReviews/ EconomicData/DocLib/Article_082017_Eng.pdf

Erdoğan, S. (2020). İktisadi büyüme ve yolsuzluk ilişkisi: Türkiye için ampirik bir inceleme. Uluslararası Ekonomi ve Yenilik Dergisi, 6(2), 211-223.

Eser, L. Y., \& .Genç, M. C. (2020). Gelir ve servet üzerinden alınan vergilerin gelir dağılımı üzerindeki etkisi: OECD ülkeleri örneği. Maliye Dergisi, 178, 224-239.

Goñi, E., López, J. H., \& Servén, L. (2008). Fiscal redistribution and income inequality in Latin America. The World Bank. (Erişim: 09.09.2020) . https://elibrary.worldbank.org/doi/abs/10.1596/1813 $-9450-4487$

Gregorio, J. D., \& Lee, J. W. (2002). Education and income inequality: New evidence from cross-country data. Review of Income and Wealth, 48(3), 395-416.

Günel, T. (2019). Türkiye'de dolaylı ve dolaysız vergilerin gelir dağılımına etkisi: Ekonometrik bir uygulama. Journal of Yasar University, 14(55), 277-287.

Joumard, I., Pisu, M., \& Bloch, D. (2013). Tackling income inequality: The role of taxes and transfers. OECD Journal: Economic Studies, 2012(1), 37-70.

Kanca, O. C., \& Bayrak, M. (2019). Vergilerin gelir dağılımı üzerindeki belirleyiciliği: Panel veri analizi. Atatürk Üniversitesi Sosyal Bilimler Enstitüsü Dergisi, 23(4) , 1495-1514.

Kwiatkowski, D., Phillips, P. C., Schmidt, P., \& Shin, Y. (1992). Testing the null hypothesis of stationarity against the alternative of a unit root. Journal of Econometrics, 54(1-3), 159-178.
Martinez-Vazquez, J., Moreno-Dodson, B., \& Vulovic, V. (2012). The impact of tax and expenditure policies on income distribution: Evidence from a large panel of countries. Andrew Young School of Policy Studies Research Paper Series, (12-30).

Narayan, P.K. (2005). The saving and investment nexus for China: Evidence from cointegration tests. Applied Economics, 37(17), 1979-1990.

Nissanke, M., \& Thorbecke, E. (2006). Channels and policy debate in the globalization-inequality-poverty nexus. World Development, 34(8), 1338-1360.

OECD (2020), OECD data. (Erişim: 20.09.2020) https://data.oecd.org/tax/tax-wedge.html

Ozturk, I., \& Acaravci, A. (2013). The long-run and causal analysis of energy, growth, openness and financial development on carbon emissions in Turkey. Energy Economics, 36, 262-267.

Pesaran, H.M., Y. Shin (1999), Autoregressive distributed lag modelling approach to cointegration analysis in: S.Storm (Ed.) Econometrics and Economic Theory in the 20th Century: The Ragnar Frisch Centennial Symposium, Chapter 11, Cambridge University Press.

Pesaran M.H., Shin, Y., R.J. Smith ( 2001). Bounds testing approaches to the analysis of level relationships. Journal of Applied Econometrics, 16, 289-326.

Prasad, N. (2008). Policies for redistribution: The use of taxes and social transfers. Available at SSRN 1358237.

Sameti, M., \& Rafie, L. (2010). Interaction of income distribution, taxes and economic growth. Iranian Economic Review, 14(25), 67-81.

Solt, F. (2020). Measuring income inequality across countries and over time: The standardized world income inequality database. Social Science Quarterly, 101(3), 1183-1199.

Teyyare, E., \& Sayaner, K. (2018). Türkiye'de gelir eşitsizliğinin maliye politikası araçları ve kurumsal faktörler açısından analizi ve çözüm önerileri. Bingöl Üniversitesi Sosyal Bilimler Enstitüsü Dergisi, 8(16), 309-334.

The World Bank (2019). World Development Indicators. (Erişim: 20.09.2020) https://databank.worldbank.org/reports.aspx?source= world-development-indicators

Zaman, T., Dünder, E., \& Aydın, S. (2019). Gini katsayısını etkileyen faktörlerin beta regresyon yöntemi yardımı ile belirlenmesi. Erzincan Üniversitesi Fen Bilimleri Enstitüsü Dergisi, 12(1), 235-240. 


\section{Extended Abstract}

In the last two decades, there has been a significant increase in income inequality in many countries around the world, and it has accelerated with the 2008 global financial crisis. Income inequality is an important issue that needs to be addressed not only from a moral and ethical perspective but also from its harmful effects on development and welfare. The most important fiscal policy tools that government has for reducing income inequality are tax policy and transfer policy. Although the main purpose of tax policy is to finance public expenditures, it is occasionally used to reduce income inequality. As income inequalities have become a worldwide problem, new literature has been raised on what kind of taxes should be used more actively for income redistribution (Prasad, 2008: 1). There is a consensus in the literature that an increase in indirect taxes increases income inequality, while an increase in direct taxes reduces income inequality. It is emphasized that income and wealth taxes which are among the direct taxes are the most effective in reducing income inequality because they take into account the individual and family situation of the taxpayer, they are progressive taxes and, their reflections are not easy (Kanca ve Bayrak; 2019: 1498; Eser ve Genç, 2020:224). Empirically testing these theoretical expectations and determining which tax is more effective in reducing income inequality will increase the effectiveness of policies to reduce income inequality. Based on this, the main purpose of this study is to reveal empirically the effect of income and wealth taxes on income distribution by using data covering the period 1987-2016 for Turkey. To the best of our knowledge, this study is the first to examine the effect of income and wealth taxes on income distribution in the case of Turkey. Therefore, it is thought to make an important contribution to the literature.

There is a relatively new and growing literature examining the impact of tax composition on macroeconomic variables. An important part of the related literature is the studies that examine the relationship between tax and income inequality. When a general evaluation is made for the studies of Gregorio and Lee (2002), Prasad (2008), Sameti and Rafie (2010), Martinez-Vazquez et al. (2012), Bilgiç (2015), Cevik and Correa-Caro (2015), Balseven and Tugcu (2017), Bükey and Çetin (2017), Drucker et al. (2017), Demirgil (2018), Teyyare and Sayaner (2018), Ciminelli et al. (2019), Günel (2019), Hook and Flag (2019) and Artifact and Young (2020), the following points draw attention: i) Most of the studies have examined the effects of indirect and direct taxes and transfer expenditures on income distribution. Although there are studies that have different findings, most of the studies have concluded that direct taxes and transfer expenditures/public expenditures reduce income inequality, while indirect taxes increase income inequality. ii) The number of studies examining the effects of income and wealth taxes on income distribution is quite limited. Also, as far as it is researched, there is no study addressing this relationship in the Turkey example. In this study, the effects of income and wealth taxes on income distribution were examined for Turkey to fill this gap in the literature and, provide an empirical contribution to the literature.

The Gini coefficient, which takes the redistribution effect into account, was used as the dependent variable in the study. This coefficient equal to the difference between the Gini market and the Gini disposable. The Gini coefficient, which takes into account the redistribution effect, shows how direct taxes and transfer expenditures affect income distribution. The share of income and wealth taxes in GDP were used as the independent variables. Also, transfer expenditures, unemployment, and inflation rates were used as control variables in the model to prevent omitted variable bias. To estimate the model with the most appropriate econometric analyses and obtain effective estimators, the stationary properties of the variables were determined firstly. ADF and KPSS unit root tests give different results for the stationarity properties of the variables. Since some of the independent variables in the model are stationary at the level and the others stationary in their first difference, the ARDL approach was used. When the results of the ARDL bound test are examined; It was determined that the most suitable model is ARDL $(2,0,2,1,1,1)$. Since the calculated F statistic value is higher than the critical upper limit value (3.38) at the 5\% significance level, the null hypothesis is rejected and it is concluded that there is a long-run relationship between the variables.

According to the long-run coefficients, an increase in income tax, wealth tax, and transfer expenditures reduces income inequality, while an increase in unemployment and inflation increases income inequality. Although income tax is more effective than wealth tax in reducing income inequality, it is observed that the coefficients are quite close to each other. On the other hand, it has been determined that the most important determinant of income distribution is unemployment. It is seen that the long-run findings obtained in the study are consistent with Gregorio and Lee (2002), Prasad (2008), Martinez-Vazquez et al. (2012), Bilgiç (2015), Demirgil (2018), Teyyare and Sayaner (2018), Ciminelli et al. (2019), Günel (2019) and Zaman et al. (2019), but not consistent with Sameti and Rafie (2010), Cevik and Correa-Caro (2015), Bükey and Çetin (2017), Drucker et al. (2017), Hook and Flag (2019) and Artifact and Young (2020).

Some policy recommendations based on findings can be listed as follows: Increasing and spreading the wealth tax will be an important factor in reducing income inequality. Policymakers can reduce income inequality by increasing sustainable employment opportunities. Well-designed transfer spending can improve income distribution by creating equal opportunities in access to education and health services. Income inequality can be reduced with policies that will provide stability at the general level of prices. 